\title{
La RSC como herramienta de gestión y comunicación de la reputación corporativa
}

\author{
Zahaira Fabiola González Romo \\ Universitat Internacional de Catalunya, Barcelona. Facultad de Comunicación. \\ zfgonzalez@uic.es
}

\begin{abstract}
Marina Taltavull Cerrudo
Universitat Oberta de Catalunya, Barcelona. Comunicación e Información.

marina_mtc@hotmail.com
\end{abstract}

Recibido: 10 de marzo de 2017. Aceptado: 1 de agosto de 2017.

\section{Resumen}

Durante la década pasada, la importancia y preeminencia global de la Responsabilidad Social Corporativa (RSC) ha ido en aumento. La RSC está integrada por naturaleza a la estrategia de negocios esencial de una empresa, y se vuelve una parte crucial del proceso de creación de riqueza, de la sustentabilidad del lucro y la generación de valor a largo plazo. Las compañías han aplicado la RSC desde el momento en que surgieron preocupaciones acerca del impacto social que tienen en las comunidades en que operan. Debido a estas exigencias, varias empresas comenzaron a elaborar informes que incluyeron de una forma $\mathrm{u}$ otra vertientes sociales y medioambientales. Del mismo modo, organizaciones de la sociedad civil y foros de grupos de interés desarrollaron recomendaciones y normas para la elaboración de estos informes que, como resultado, han dado lugar a varias iniciativas internacionales y a sistemas específicos de gestión ambiental.

En este trabajo se estudia la RSC en el ámbito del comportamiento de las empresas medioambientales, profundizando en el concepto y los diferentes enfoques teóricos, su aplicación en el sector privado y en el sector público, y los principales modelos de medición y gestión; además del análisis práctico de la aplicación de la RSC en una empresa medioambiental como es CESPA (Ferrovial), una de las primeras empresas españolas del sector.

Palabras clave: RSC, RSE, responsabilidad corporativa, responsabilidad empresarial, responsabilidad social, cultura corporativa, sistemas de medición, sistemas de certificación, desarrollo sostenible, medio ambiente, gestión ambiental, stakeholders. 


\title{
CSR as a tool for managing and communicating corporate reputation
}

\begin{abstract}
For the past decade, there has been an increase in the importance and global predominance of Corporate Social Responsibility (CSR). By its very nature, CSR tends to be integrated into a company's core business strategy, becoming a crucial element in the process of long-term wealth creation, profit sustainability, and value creation. Companies started applying CSR in response to widespread concern about their impact on society. For this reason, many began drafting reports that, in one way or another, contemplate social and environmental aspects. In turn, civil society organizations and stakeholder forums developed recommendations and standards for these reports, which, as a result, have led to numerous international initiatives and specific systems of environmental management. This paper looks at CSR in the context of how environmental companies behave. It examines the concept in depth and thoroughly considers different theoretical approaches, the concept's application in the private and public sectors, and its main measurement and management models. We also offer a practical analysis of the application of CSR in an environmental company like CESPA (Ferrovial), one of the first such companies in Spain. Keywords: CSR, corporate responsibility, corporate responsibility, social responsibility, corporate culture, measurement systems, certification systems, sustainable.
\end{abstract}

\section{A RSE como uma ferramenta para a gestão e a comunicação da reputação corporativa}

\section{Resumo}

Durante a última década, a importância global da Responsabilidade Social Empresarial (RSE) tem vindo a aumentar. RSE é integrada por natureza á estratégia de negócios essencial de uma empresa, e se torna uma parte crucial do processo de criação de riqueza, da sustentabilidade do lucro e da geração de valor em longo prazo. As empresas têm implementado RSE, a partir do momento em que preocupações sobre o impacto social nas comunidades em que atuam emergiram. Devido a esses requisitos, várias empresas começaram elaborar relatórios que incluíram, de uma forma ou de outra, vertentes sociais e aspectos ambientais. Da mesma forma, as organizações da sociedade civil e fóruns de grupos de interesse, desenvolveram recomendações e normas para a elaboração desses relatórios que, como resultado, acabaram em várias iniciativas internacionais e sistemas específicos de gestão ambiental. Neste trabalho estudamos a RSE no campo do comportamento das empresas ambientais, aprofundando o conceito e as diferentes abordagens teóricas, a sua aplicação no setor privado e no setor público, e os principais modelos de medição e de gestão; além da análise prática da implementação da RSE em uma empresa ambiental como CESPA (Ferrovial), uma das primeiras empresas espanholas do setor.

Palavras chave: RSC, RSE, responsabilidade corporativa, responsabilidade social, responsabilidade empresarial, cultura corporativa, sistemas de medição, sistemas de certificação, desenvolvimento sustentável, meio ambiente, gestão ambiental, stakeholders.

\section{Introducción}

Desde la década de 1980, la noción de Responsabilidad Social Corporativa (RSC) ha ido cobrando un protagonismo creciente en diferentes ámbitos académicos y empresariales y ha sido objeto de múltiples aproximaciones conceptuales (Correa, 2007). 
Si bien inicialmente su aplicación era voluntaria y se fundamentaba, casi con exclusividad, en las implicaciones en términos de "buena reputación" que conllevaba, con el paso de los años ha ido adquiriendo un carácter obligatorio y se ha convertido en un elemento central de la visión estratégica de numerosas organizaciones -especialmente del sector privado- que pretenden, con ello, aumentar su valor añadido y mejorar su situación competitiva. Por este motivo, la RSC es vista, al mismo tiempo, como un instrumento mitigador de los riesgos empresariales y como una fuente de oportunidades de negocio que permite a las empresas diferenciarse de su competencia a través del manejo de su reputación (Suárez \& Pérez, 2010). La definición y la aplicación de un código de gestión socialmente responsable ha alcanzado, si cabe, una mayor importancia en la esfera de las empresas medioambientales, dada la exigencia que tienen estas organizaciones de integrar en su quehacer cotidiano los valores y principios propios del desarrollo sostenible. En cambio, la aplicación de la RSC en el ámbito del sector público debe recorrer un largo camino, pues todavía son pocas las administraciones públicas conscientes de la relevancia social que conllevan la definición, la ejecución y la divulgación de políticas de gestión responsables y sostenibles entre sus públicos de interés (Cueto, 2014).

Todo esto ha conducido a un reciente estudio sobre el estado de la RSC en España (Silos, 2015), auspiciado por la asociación empresarial Forética, el cual concluye que nos encontramos en el inicio de una nueva etapa en la que una de las prioridades de la agenda mundial radica en llegar a acuerdos de ética global en materia de objetivos de desarrollo sostenible, de lucha contra el cambio climático, de mejora de la transparencia y de reducción de la desigualdad, entre otros. La RSC constituye pues un tema de gran relevancia, tanto en el debate académico como en las esferas profesionales y empresariales.

Dada la tendencia comentada, las organizaciones que quieran ser socialmente responsables habrán de implementar diversos procedimientos y deberán llevar a cabo distintas acciones que queden englobadas dentro del concepto de responsabilidad corporativa, atendiendo a su tamaño, tipología y recursos. Según Argandoña (2008, “[...] cada empresa debe diseñar y poner en práctica sus propias políticas, planes y acciones de responsabilidad social: no vale el café para todos" (p. 14). En este proceso de elaboración y ejecución del plan estratégico, resulta indispensable que las empresas identifiquen y tengan presentes a sus stakeholders y a su "ciudadanía corporativa", nociones que han devenido claves en los análisis teóricos de la RSC (Capriotti \& Schulze, 2010).

Entre las múltiples aproximaciones teóricas que tratan de aprehender las actividades de RSC llevadas a cabo por las empresas, conviene destacar la teoría del valor para el accionista, la teoría instrumental de stakeholders, la teoría normativa de stakeholders y la teoría de la ciudadanía corporativa (Cueto, 2014). Estas teorías se basan en enfo- 
ques distintos que Garriga y Melé (2004) proponen clasificar según enfaticen el papel de los beneficios, de la actuación política, de las demandas sociales y de los valores éticos.

Con todo, ¿cómo determinar si una empresa es socialmente responsable e, incluso, si tiene integrada una correcta política ambiental? Existen distintos sistemas de medición y gestión que permiten evaluar, de forma continua en el tiempo, las medidas adoptadas por las organizaciones con el fin de instituir una cultura corporativa responsable y mejorar el comportamiento medioambiental de las empresas (Gómez, 2009). De ahí que, como ha subrayado Argandoña (2008), “[...] la RSC no es una meta que se alcanza sino una forma de actuar continua y responsable” (p. 32).

\section{Objetivos de investigación}

La finalidad principal de la presente investigación es analizar y valorar la RSC desde una visión teórica y generalizada del concepto, y desde una visión más específica y especializada, centrándose en el sector medioambiental; aprovechando el contexto actual en el que la RSC representa una nueva manera de gestionar las compañías y su comunicación.

Así pues, esta investigación tiene como objetivos generales recapitular los principales enfoques teóricos sobre la RSC y los modelos de medición y gestión más relevantes que permiten valorar el grado de responsabilidad social y ambiental de una compañía, así como su reputación.

De forma más concreta, el trabajo persigue tres objetivos específicos: el primero, definir el marco teórico en el que se ha desenvuelto el debate académico en torno a la RSC, explicando las cuatro grandes teorías que lo caracterizan (teoría del valor para el accionista, teoría instrumental de stakeholders, teoría normativa de stakeholders y teoría de la ciudadanía corporativa) y examinando la lógica de la acción desempeñada por los agentes que tienen una mayor incidencia en el diseño de los planes estratégicos que implantan las empresas socialmente responsables (stakeholders y ciudadanía corporativa). Asimismo, dado que a partir de unas normas cada empresa desarrolla sus respectivos programas de responsabilidad social, se investiga la aplicación de la RSC en el ámbito del medioambiente, tanto en el sector privado como en el sector público, estableciendo el alcance de esta en cada uno de ellos.

El segundo objetivo específico consiste en definir los principales sistemas de medición de la RSC y de la gestión ambiental establecidos y reconocidos tanto a nivel europeo como a nivel mundial. Este análisis nos ha de permitir alcanzar un entendimiento de los instrumentos más relevantes de aplicación de la RSC, identificando sus ventajas y desventajas. En particular, se analizan con detalle el Pacto Mundial, Global Reporting Initiative, Libro verde, AA1000 AccountAbility, Directrices de la OCDE, SA 
8000, Norma SGE 21, ISO 26000, Norma ISO 14001 y Eco-Management and Audit Scheeme.

Como tercer y último objetivo específico, se presenta, a modo de estudio de caso, la política de RSC desarrollada por la empresa CESPA, perteneciente al grupo empresarial Ferrovial. Con su dilatada experiencia en el sector y sus consolidadas prácticas de Responsabilidad Social Corporativa, esta compañía constituye un claro e interesante ejemplo de estudio. Entre los aspectos a los que se dedica atención, caben destacar las líneas estratégicas de RSC, sus implicaciones empresariales, los instrumentos de gestión y las acciones puestas en marcha para comunicarlas.

\section{Metodología, fuentes y estructura}

La metodología del trabajo se fundamenta en el método deductivo, ya que se parte de unas ideas generales que luego son aplicadas a un caso concreto de estudio.

Con el fin de que tanto la RSC como su propia aplicación en el sector de las empresas medioambientales puedan ser objeto de un estudio coherente y contrastado, se remite a una base académico-profesional y a teorías y experiencias que el mundo empresarial ha ido consolidando, de forma que se crea una bibliografía de múltiples referencias. De este modo, se utilizan tanto fuentes primarias (documentación empresarial, normativas y entrevistas personales, entre otras) como secundarias (bibliografía sobre el tema). La investigación tiene un enfoque cualitativo y una aproximación multidisciplinar, ya que se recurre a una bibliografía procedente de diferentes ciencias sociales (economía, sociología, política). Para profundizar en el caso de estudio de la empresa CESPA, se hizo contacto con los responsables del sistema de gestión medioambiental, con quienes se mantuvieron diversas reuniones y entrevistas para explicar las vías de aplicación y el alcance de la Responsabilidad Social Corporativa.

El trabajo se estructura en seis apartados. En primer lugar, se presentan las principales aportaciones teóricas que han caracterizado el debate académico sobre la RSC, haciendo especial hincapié en las aproximaciones que han analizado la aplicación de este concepto en el sector de las empresas medioambientales. En segundo lugar, nos centramos en la aplicación de los supuestos de la RSC en el ámbito de la gestión -tanto pública como privada- del medio ambiente. En tercer lugar, se examinan los principales modelos de medición y gestión de la RSC, atendiendo tanto a las regulaciones internacionales de carácter genérico como a los sistemas específicamente enfocados a la gestión ambiental. En cuarto lugar, se realiza el estudio de caso ya señalado sobre el diseño, la aplicación y los resultados de la política de RSC implantada por la empresa CESPA. A modo de resultados, en quinto lugar se realiza una recapitulación de los aspectos más relevantes tratados en la investigación, y por último se exponen, a la vista 
del estudio de caso abordado, luces y sombras de la aplicación de la RSC en la sociedad contemporánea como herramienta de comunicación de la reputación empresarial.

\section{La Responsabilidad Social Corporativa, concepto y enfoques}

La RSC renueva la concepción de la empresa, otorgando a esta una dimensión amplia e integradora, que va más allá de la mera cuestión económica en la que se incorpora perfectamente la triple faceta de la sostenibilidad: económica, social y medioambiental.

A continuación, estudiaremos el concepto de la RSC, los diversos enfoques teóricos y las principales aportaciones teóricas de su contribución al desarrollo sostenible.

\section{Conceptualización de la RSC}

Se entiende la RSC como la contribución activa y voluntaria al mejoramiento social, económico y ambiental de las empresas, generalmente para mejorar su situación competitiva, valorativa y su valor añadido.

Según publica la Asociación Española de Contabilidad y Administración de Empresas (AECA) en el documento de Marco Conceptual de la Responsabilidad Social Corporativa (2004) la RSC es "[...] el compromiso voluntario de las empresas con el desarrollo de la sociedad y la preservación del medio ambiente, desde su composición social y un comportamiento responsable hacia las personas y grupos sociales con quienes se interactúa" (p. 21).

$\mathrm{Al}$ igual que la definición anterior, otros autores profundizan más y recalcan no solo la conducta respetuosa del medio ambiente, sino de la legalidad, la ética y la moral. (Alea, 2007). Hay quienes especifican el alcance de la RSC en los ámbitos económico, social y medioambiental, además de la transparencia informativa respecto a los resultados alcanzados y su escrutinio externo (Lafuente et al., 2003).

Así pues, son un gran número de autores los que han estudiado y analizado la RSC, de lo que se deducen cientos de definiciones que tratan de explicar su significado.

Sin duda alguna, la visión de la RSC ha ido progresando con el tiempo: su origen parte de ciertos principios fundamentales como la filantropía para hacer el bien social. Estas empresas anticiparon políticas sociales que posteriormente se convertirían en normas de obligado cumplimiento, como las que hizo uno de los empresarios más importantes, Henry Ford (Cancino \& Morales, 2008; Domínguez \& Fernández, 2011).

Explicada la evolución de la RSC de forma breve, se puede afirmar que ha sido considerada como un nicho de mercado más desde el que aumentar la cifra de negocio, para llegar adonde no llegaba el Estado de Bienestar, pero también se ha diluido a favor de un modelo puramente accionarial, para volver a resurgir como una poderosa 
herramienta de marketing, comunicación y de mejora de la reputación empresarial (Domínguez \& Fernández, 2011).

Durante esta evolución histórica de la RSC, surgen posturas y enfoques opuestos por distintos autores: algunos filósofos, economistas y académicos plantean como único objetivo de las compañías la obtención de beneficios, es decir, maximizar el valor de su capital (Moneva, 2008). Friedman, uno de los economistas más brillantes del siglo XX, escribió en 1970 un conocido artículo, "The Social Responsibility of Business is to Increase its Profits", en el que razonó, como bien explica Argandoña (2006):

\begin{abstract}
Las empresas, como instituciones económicas, deben contribuir a la eficiencia del sistema económico, y esto se consigue, bajo ciertas condiciones, cuando maximizan sus beneficios. No hay lugar pues para otras responsabilidades y en concreto para el ejercicio de la llamada acción social o filantropía: la participación de la empresa en actividades caritativas o de mecenazgo supone, al menos, un incumplimiento del deber fiduciario de los directivos respecto de los propietarios y, probablemente, un uso ineficiente de los recursos de la empresa (p. 6).
\end{abstract}

Otros, sin embargo, califican de inadecuado el enfoque de Friedman y proponen otro diferente. Donaldson introduce objetos morales en la estructura corporativa de toma de decisiones. Caroll, expresa cuatro dimensiones principales que caracterizan la responsabilidad que la empresa debe asumir ante la sociedad: económica, legal, ética y discrecional (Moreno et al., 2007).

Los últimos desarrollos conceptuales tienden a priorizar nuevas dimensiones de la RSC como Vieira, que propone la aceptación de la necesidad de un nuevo modelo de desarrollo que tome en consideración la necesidad de cuidar mucho más el impacto económico, social y ambiental de las actividades empresariales (Chirinos et al., 2012), y Malagón, que explica que la RSC y la generación de valor (uno de los objetivos centrales de las organizaciones) no se oponen con la búsqueda del bien común (Avendaño, 2011). Asimismo, Porter y Kramer (2006) apuntan a que la RSC debe promoverse fundándola en una comprensión amplia de la interrelación entre la sociedad y una corporación, a la vez que se ancla en las estrategias y actividades de empresas específicas, y Lucía (2015) que realza el valor de la transparencia en RSC, manifestando que a través de la transparencia la empresa incrementa y asegura su desempeño social y mejora su reputación.

A la vista de los antecedentes teóricos señalados, a lo largo de esta investigación se considerará la RSC como un conjunto de comportamientos y actividades de negocio (filosofía corporativa adoptada por la alta dirección de una empresa) basados en valores éticos y principios de transparencia que incluyen una estrategia de mejora continua en la relación entre la empresa y sus partes. 


\section{Enfoques teóricos sobre la RSC}

Existe una impresionante historia asociada a la evolución del concepto y la definición de la RSC, con una gran variedad de teorías y enfoques que explican las actividades de RSC que llevan a cabo las empresas, actividades que son de carácter económico o meramente social y ético (Cueto, 2014).

A continuación, sistematizaremos las teorías en cuatro grupos, relacionados con los beneficios, la actuación política, las demandas sociales y los valores éticos; profundizando en cada una de ellas tanto a nivel de definición como de análisis de las visiones alternativas que tienen algunos de los autores más representativos.

En un extremo están los autores que dicen que el propósito del negocio es aumentar los beneficios o aumentar el valor para sus accionistas, y la tarea de mejorar el bienestar público en su conjunto debe ser dirigida principalmente por el gobierno, organizaciones sin fines de lucro y las instituciones religiosas. En el otro extremo, los autores que creen que el negocio tiene una gran obligación social, cívica y moral para el crecimiento del bienestar general en un amplio contrato social (Madrakhimova, 2013).

\section{Teoría del valor para el accionista}

Ateniéndose a la ley y la costumbre ética, esta teoría se trata de la incrementación de los beneficios para los accionistas. La preocupación de las empresas se centraliza en la obtención de beneficios económicos o creación de valor para el accionista (Cueto, 2014).

Garriga y Melé (2004) consideran que esta teoría tiene un enfoque instrumental, en el que la empresa es vista exclusivamente como un instrumento de creación de riqueza y apuesta por un comportamiento ético y responsable en la medida en que este comportamiento aporte ventajas competitivas al negocio.

En palabras de Friedman, "hay una y solo una responsabilidad de la empresa: usar sus recursos en actividades encaminadas a maximizar sus beneficios, en la medida en que observe las reglas del juego, es decir, que actúe dentro de la libre competencia, sin engaño ni fraude" (Argandoña, 2005, pp. 1-2).

Para Cancino y Morales (2008), las empresas buscan desarrollar actividades de RSC que estén ligadas a la obtención de mayores beneficios económicos para sus accionistas; lo que crea una relación directa entre RSC y creación de riqueza, por lo que únicamente el aspecto económico de la interacción entre la sociedad y la empresa es el que importa al momento de llevar a cabo el negocio.

Sin embargo, otros autores manifiestan una visión matizada sobre esta teoría, como Gismera y Vaquero (2000) quienes consideran que las empresas no deberían centrarse solo en la maximización del beneficio, sino que deberían maximizar el beneficio de los stakeholders: "las empresas deben buscar de forma activa hacer el bien y promover 
fines sociales, como el fomento del empleo, la disminución de la contaminación y que los productos que fabriquen tengan una calidad óptima" (p. 2).

Porter y Karmer (2011), que creen que las empresas deben buscar un equilibrio entre necesidades sociales y beneficios empresariales; un nuevo concepto al que denominan valor compartido.

\section{Teoría instrumental de stakeholders}

La responsabilidad de la empresa debe además expandirse a la búsqueda de valor para todos los implicados en ella, es decir, para los stakeholders (Cueto, 2014), sostiene esta teoría instrumental.

Freeman y Mcvea (2001) afirman que, en esta teoría, una deficiencia evidente es el problema de la identidad de las partes interesadas, debido a que es difícil distinguir a aquellos individuos y grupos que son stakeholders de aquellos que no lo son. Asimismo, añaden que autores como Logsdon y Wood (2002) abordaron esta cuestión desarrollando un marco para la identificación de las partes interesadas. Usando criterios cualitativos de poder, legitimidad y urgencia, desarrollaron lo que estos autores llaman "el principio de quién y qué realmente cuenta". Esta línea de investigación es particularmente relevante en áreas como el medio ambiente y el activismo político de base. La cuestión crítica es si existe un stakeholder ilegítimo y, de ser así, cómo debe definirse la legitimidad.

Freeman \& Mcvea (2001), además, han ido modificando ligeramente a lo largo del tiempo su concepto de stakeholder: aunque ha seguido siendo fiel a sus definiciones originales, apunta a que la empresa debe atender todos los grupos o individuos que puedan afectar o ser afectados por el logro de los objetivos de la compañía. Como stakeholders incluye a empleados, clientes, proveedores, accionistas, bancos, ambientalistas, gobierno u otros grupos que puedan ayudar o dañar a la compañía. Cree que, atendiendo la empresa a las demandas de sus grupos de interés, se obtienen mejores resultados en la coordinación y priorización de los stakeholders multilaterales, consolidando la posición competitiva (Argandoña, 2009).

Garriga y Melé (2004) consideran, en este caso, que el enfoque de la teoría es integrador, puesto que la empresa se centra en la captación, la identificación y la respuesta a las demandas sociales, es decir en la satisfacción de las demandas sociales de sus stakeholders, pretendiendo legitimidad social y una mayor aceptación y prestigio social.

Y por su lado, Cancino y Morales (2008), plantean que en la teoría instrumental de stakeholders una serie de trabajos buscan explicar el desarrollo de actividades de RSC por el deseo de integrar diversas demandas sociales, entre las cuales cabe mencionar el cumplimiento de las leyes, las políticas públicas y la gestión balanceada de los intereses particulares de los grupos de interés de una empresa. 


\section{Teoría normativa de stakeholders}

Esta teoría se basa en la ética empresarial, en la que la RSC tiene un fundamento más social que económico. La RSC debe abarcar las categorías económica, legal, ética y discrecional de la sociedad sobre la organización, en el sentido de intención deliberada del desempeño del negocio (Carroll, 1979). Y es que para Carroll (1983),

la RSC implica la conducción de un negocio para que sea económicamente rentable, respetuoso de la ley, ético y solidario. Ser socialmente responsable entonces significa que la rentabilidad y la obediencia a la ley son las condiciones más importantes cuando se discute la ética de la empresa y en qué medida apoya la sociedad en la que existe con aportaciones de dinero, tiempo y talento (p. 608).

Garriga y Melé (2004) defienden esta teoría como un enfoque ético y moral que se fundamenta en la responsabilidad ética de las empresas frente a la sociedad, en los principios que expresan qué se debe y qué no se debe hacer o la necesidad de construir una sociedad mejor. En la misma línea, Cancino y Morales (2008) sugieren que esta teoría parte del desarrollo de actividades de RSC en respuesta al cumplimiento de derechos universales, como el respeto de los derechos humanos, los derechos de la fuerza del trabajo y el respeto por el medio ambiente, entre otros. Se trata de acciones correctas en beneficio del bien común.

\section{Teoría de la ciudadanía corporativa}

Esta perspectiva teórica considera que la empresa debe ser parte de la sociedad y tiene obligaciones sociales, como son la equidad, la justicia social y la protección de los trabajadores. Así pues, sus actuaciones han de contribuir de forma socialmente responsable al bienestar de las comunidades en la que se instalan (Cueto, 2014).

Cancino y Morales (2008) exponen que es una teoría de carácter político, donde se acentúa el poder social que adquiere la compañía en la medida que se ve inserta en una sociedad.

El concepto de RSC está reemplazándose por un nuevo concepto de ciudadanía corporativa. Asimismo, el contenido central de la RSC también está sustituyéndose gradualmente en una parte significativa de la literatura por un concepto más estrecho y voluntarista de servicio a la comunidad corporativa. Así pues, la ciudadanía corporativa contiene una fuerte orientación moral, realidades estructurales e institucionales, y la flexibilidad necesaria para responder a las estructuras y dinámicas de las relaciones entre las empresas y las partes interesadas. La ciudadanía corporativa establece un análisis de las relaciones entre los negocios y la sociedad, es decir sobre cómo enfrentan las compañías y la sociedad sus derechos y deberes (Logsdon y Wood, 2002). 
Garriga y Melé (2004), con un enfoque político, determinan que este tipo de teorías se centran en el poder de las empresas en la sociedad y el uso responsable de este poder en el escenario político.

\section{La RSC y su contribución al desarrollo sostenible: principales aportaciones teóricas}

Según Ricart y Rodríguez (2002), una empresa sostenible es aquella que integra los valores o principios como sostenibilidad (búsqueda permanente del desarrollo económico, la integridad medioambiental y el bienestar social), visión a largo plazo, diversidad (de opiniones, culturas, perspectivas, edades y sexos en su organización y en las relaciones con su entorno), apertura en diálogo con las partes interesadas (stakeholders), integridad y responsabilidad.

La responsabilidad social de las implicaciones ambientales es muy relevante por el impacto directo sobre el desarrollo económico y social de países en vías de desarrollo. La experiencia demuestra que las empresas que desarrollan prácticas de protección medioambiental son más competitivas en el mercado internacional, en la medida en que el respeto de las normas en este ámbito estimula la innovación y la modernización de los procesos y los productos, y fomenta el uso de tecnologías más limpias. Del mismo modo, las empresas internacionales competitivas están en mejores condiciones de invertir en nuevas tecnologías, más eficientes y limpias (Casado, 2006:107).

Así pues, cualquier decisión y acción que tome la empresa tiene un impacto sobre el medio ambiente, ya sea a través del consumo de los recursos naturales (inputs como materias primas, energía, etc.) o a través de emisiones atmosféricas, vertidos de residuos, aguas residuales (outputs como contaminantes). La empresa debe contribuir al desarrollo sostenible (Fernández, 2008).

Según el Consejo Mundial de Negocios para el Desarrollo Sostenible, World Bussiness Council for Sustainable Development (WBCSD, 2016), incorporar el concepto de ecoeficiencia a la estrategia empresarial supone proporcionar bienes y servicios a un precio competitivo, que satisfaga las necesidades humanas y la calidad de vida, al tiempo que reduzca progresivamente el impacto ambiental y la intensidad de la utilización de recursos a lo largo del ciclo de vida, hasta un nivel compatible con la capacidad de carga estimada del planeta. La gestión ecoeficiente incide positivamente sobre la competitividad de la empresa porque propicia la mejora continua a través de la reducción del derroche de recursos: disminuye el volumen de residuos generados, el consumo energético y de agua y, por tanto, el impacto ambiental que su actividad pueda generar.

Para Díaz i Pont (2007), la misión y el reto de la empresa sostenible es encontrar oportunidades que resulten beneficiosas tanto para ella como para la sociedad y el medio en los cuales operan, ampliando la visión de la sostenibilidad limitada a la gestión del riesgo. 
En este sentido, la empresa ha de estar alineada hacia la consecución de objetivos de triple base: económicos, ambientales y sociales; pues como plantea también la Organización de las Naciones Unidas para la Educación, la Ciencia y la Cultura (UNESCO, 2015), todos los programas para el desarrollo sostenible deben considerar estos tres ámbitos de la sostenibilidad, además de una dimensión subyacente de la cultura.

La Asamblea General de Naciones Unidas adoptó en 1987 la primera definición de sostenibilidad, la cual aparece en el Informe Brundtlan (en homenaje a Gro Harlem Bruntland, política noruega que dirigió la redacción del informe Nuestro Futuro Común) y hace referencia al desarrollo sostenible como aquel que "satisface las necesidades del presente sin comprometer la capacidad de las generaciones futuras de satisfacer sus propias necesidades" (Alea, 2007).

Por su parte, Pinillos y Fernández (2011) entienden la sostenibilidad corporativa como "una evolución natural y necesaria de la responsabilidad social corporativa para vincularla más al valor y al core business de cada empresa." Asimismo, consideran necesarias cuatro premisas básicas para que la sostenibilidad corporativa se despliegue en su dimensión y establezca una relación de causa (gestión responsable y sostenible) a efecto (más ingresos, menos costes, mayor satisfacción del cliente, mejor clima laboral). La primera premisa es cambiar el lenguaje de los profesionales de la RSC, olvidar el concepto de "buenismo"'; la segunda, construir el modelo de negocio de la sostenibilidad, dado que es el factor más importante en el éxito; la tercera de ellas, cambiar el modelo de gestión de la RSC, invirtiendo en proyectos sociales al igual que se invierte en I+D; y la última, exige a la sostenibilidad superar su origen medioambiental.

Por último, cabe destacar como dato que, en el año 2010, $\mathrm{KPMG}^{2}$ y la revista británica The Economist realizaron un estudio en el cual fueron entrevistados 378 directivos de empresas de diversos tamaños en todo el mundo, para conocer qué actividades habían desarrollado sus organizaciones en el campo de la RSE. Las acciones más preponderantes se encontraban en el ámbito medioambiental y, en último lugar, estaban aquellas relacionadas con el aumento del impacto en las comunidades locales, con un 61\% (Schneider, 2011).

\section{La Responsabilidad Social Corporativa en el ámbito de la gestión ambiental}

La preocupación por los aspectos sociales y medioambientales por parte de la sociedad ha aumentado en los últimos años, y las responsabilidades en este sentido atribuidas al sector privado y público se encuentran en continua mejora.

\footnotetext{
El buenismo es una tendencia de pensamiento carente de autocrítica corporativa, que persigue hacer el bien a todos los stakeholders sin ninguna justificación estratégica.

2 KPMG es una red global de firmas de servicios profesionales que ofrece servicios de auditoría, de asesoramiento legal y fiscal, y de asesoramiento financiero y de negocio en 156 países. Es una de las cuatro firmas más importantes del mundo de servicios profesionales.
} 
Si bien el concepto de RSC está ampliamente extendido en el sector privado y en cambio, en el sector público aún no hallamos una extensa literatura ni demasiados ejemplos, aunque ya encontramos iniciativas de puestas en práctica.

En este punto, consideramos importante prestar atención a estos dos sectores y analizar la aplicación de la RSC en ambos casos.

\section{Aplicación en el sector privado}

Desde el punto de vista de Aranda (1994), una de las cuestiones que dificultan la descripción y el análisis del sector privado medioambiental es la ausencia de una definición precisa, aunque Ludevid (2000) define este sector como aquel que comprende "[...] las empresas y actividades económicas dedicadas a la prevención (ex ante), a la mitigación (durante) y a la reparación (ex post) de los problemas creados a los sistemas naturales por las actividades humanas" (p. 201). Otros autores también describen el sector medioambiental como el conjunto de actividades dedicadas a la producción de bienes y servicios para los propósitos medioambientales (Garcés y Ramírez, 2002).

El Ministerio de Agricultura y Pesca, Alimentación y Medio Ambiente de España, en la misma línea de las definiciones anteriores, incorpora además los sectores de actividad que deben ser considerados, entendiendo por sector o industria medioambiental: “[...] el conjunto de actividades de producción y comercialización de bienes y servicios relacionados con el medio ambiente" (Garcés y Ramírez, 2002); definición que considera tanto el grupo de bienes de capital (construcciones, maquinaria, bienes de equipo, etc.) y bienes de consumo (materias primas, materias auxiliares, eco-productos, etc.), como el de servicios (de recogida y tratamiento de residuos, de tratamiento de aguas residuales, actividades de reciclaje, servicios de ingeniería y consultoría, $\mathrm{I}+\mathrm{D}$, educación, formación e información ambiental) (Garcés y Ramírez, 2002).

La Comisión Europea va más allá y en el año 2006 delimita las actividades que comprenden este sector. Bajo la premisa de "Gestión de la contaminación" se identifican nueve sectores eco-industriales, que son los siguientes: gestión de residuos sólidos y reciclaje; tratamiento de aguas residuales; control de la contaminación del aire; administración pública; gestión medioambiental privada; rectificación y descontaminación de suelos, aguas subterráneas; control de ruidos y vibraciones; investigación y desarrollo medioambiental, y monitorización medioambiental. Y bajo la categorización de "gestión de los recursos" incluye cinco sectores eco-industriales (visión de prevención): "suministro de agua; materiales reciclados; producción de energías renovables; protección de la naturaleza, y eco-construcción” (GREEN, 2009, p. 4).

En lo que respecta a la aplicación de la RSC en el sector privado, autores como Adams et al. (1998) realizaron investigaciones y determinaron que hay varios factores de la empresa que pueden influir en la forma de divulgación de información social (te- 
mas relacionados con la comunidad y el medio ambiente) como: el tamaño, que cuanto mayor sea la empresa, mayor es el nivel de información; el sector, pues las empresas que utilizan los recursos naturales limitados tienen a publicar más información sobre problemas ambientales, y el grado de participación de los sindicatos que influyen en la divulgación de los problemas de los trabajadores. Por tanto, a medida que aumenta la sensibilidad al medio ambiente, las empresas tienden a revelar más información positiva acerca de la RSC (Travassos, 2014).

\section{Aplicación en el sector público}

La Comisión Europea en su Comunicación (COM, 2002) propuso la integración de la RSC en todas las políticas de la UE, incluida en la política de administraciones públicas. Las administraciones públicas y la propia comisión deben integrar los principios de responsabilidad social en sus propios sistemas de gestión y en las relaciones con sus interlocutores. En este sentido, la administración europea ha decidido aplicar un enfoque más integrado y sistemático de la gestión de las cuestiones sociales y medioambientales en su propia administración, participando en el sistema de gestión y auditoría ambiental e invitando a otras autoridades públicas a seguir su ejemplo. Además, la comisión ha manifestado su intención de integrar firmemente las prioridades sociales y medioambientales en su gestión (inclusive en sus propios procedimientos de contratación pública) y evaluar sus resultados sociales y medioambientales. Asimismo, ha invitado a las administraciones públicas a nivel nacional, regional y local a que examinen también sus prácticas con vistas a la integración de consideraciones de tipo social y medioambiental (Navarro Hernández, 2005).

Y es que las administraciones públicas, por su función y naturaleza social, juegan un papel vital en la sociedad. Además, son una parte importante del mercado cuyos principales financiadores son los ciudadanos. Todo ello destaca la importancia de que las administraciones públicas lideren el proceso de desarrollo de la RSC, integrando y promocionando los principios de RSC en las relaciones con sus interlocutores y en sus propias actividades, actuando como modelo de comportamiento y siendo ejemplo en el entorno que les rodea (Aznar \& Galiano, 2001).

Las administraciones públicas también solicitan a las grandes empresas que colaboren en proyectos de interés social y, como cliente, se puntúan de forma positiva los certificados que la empresa tenga en materia de RSC a la hora de revisar y evaluar las ofertas en las concesiones y licitaciones públicas de obras o servicios. Se trata de una muestra significativa del reconocimiento que un grupo importante de interés, como la administración pública, puede hacer en beneficio de las empresas que demuestran un adecuado comportamiento en materia de RSC, y que sin duda le pude ayudar a ganar posiciones competitivas (Marín \& Rubio, 2008; Moreno, 2004). 
Esta tendencia es apreciable cada día más en el ámbito internacional, pues de las principales instituciones de presencia pública muchas están desarrollando directrices y orientaciones estrechamente relacionadas con la RSC (Moreno, 2004).

\section{Modelos de Medición y Gestión de la RSC}

Del mismo modo que la gestión en una empresa debe ser medida, también la gestión de la RSC puede y debe ser medida y evaluada. La medición es una tarea fundamental para conocer el grado de cumplimiento de los objetivos empresariales. Gestionar sin medir supone gestionar sin ningún tipo de criterio para determinar si se están alcanzando los objetivos. En términos generales, podemos decir que un indicador es una variable numérica que aporta información más allá del dato y que sirve, por tanto, para conocer y analizar una realidad o fenómeno que está teniendo lugar (Strandberg, 2010).

Actualmente, la sociedad demanda a las empresas la implantación de políticas de responsabilidad social, por lo que las organizaciones, nacionales e internacionales, necesitan demostrar a sus grupos de interés transparencia, ética, integridad y criterios de sostenibilidad económica, social y medioambiental. Las empresas esperan que este compromiso, adoptado voluntariamente, contribuya a incrementar su rentabilidad (González et al., 2013).

Así pues, para poder cuantificar de manera objetiva estos criterios, es necesario disponer de sistemas que ayuden a la alta dirección a medir y muestren la evolución del comportamiento de la compañía de manera objetiva, permitiendo detectar las posibles áreas de mejora, tomar decisiones al respecto y poner en marcha una serie de planes de acción para minimizar las diferencias detectadas (González et al., 2013). Según propone Stransberg (2010), esto puede realizarse según criterios desarrollados por la propia empresa o según normas establecidas, con la diferencia de que, si una empresa trabaja con sus propios criterios, en vez de con una norma establecida, debe explicar cómo se han identificado y se han medido los indicadores; mientras que si, por el contrario, utiliza una norma, esta información ya está incluida en ella. En palabras de esta autora, "[...] una norma considerada legítima ofrece credibilidad a la empresa, dado que presupone el cumplimiento de unos requisitos establecidos” (p. 8).

Strandberg (2010) añade que los indicadores deben cumplir tres requisitos para lograr su objetivo: ser fiables, comparables y tener validez. Ligteringen y Zadek (2005), dos autores muy influyentes en esta materia, sustentan que el uso de estos indicadores tiene dos motivos: ayudar a gestionar y a implementar prácticas de negocio más responsables y transparentes, y a proveer una visión clara sobre cuáles son los principales conceptos del desarrollo sostenible y la RSC. 
A continuación, profundizaremos en las principales regulaciones internacionales y sistemas específicos de gestión ambiental, deteniéndonos en cada uno de ellos.

\section{Principales regulaciones internacionales}

En la actualidad son muchas las regulaciones de carácter internacional que definen las directrices de una cultura responsable en todo tipo de organización. Sus resultados son diversos y se diferencian básicamente en los pasos de gestión tratados y las dimensiones de sostenibilidad cubiertas. La perspectiva de este apartado es de sistematización, por lo que la caracterización de las iniciativas es descriptiva y analítica.

\section{Pacto Mundial}

Pinillos y Fernández (2011) creen que todo el movimiento de la responsabilidad social empezó con el Pacto Mundial, también conocido como Global Compact, que fue lanzado por las Naciones Unidas en 1999 y que actuó como desencadenante de todos los instrumentos multilaterales e internacionales que abordaremos en los próximos apartados (Global Reporting Initiative, Libro verde, Directrices de la OCDE, etc.).

Este Pacto está compuesto por diez principios basados en las declaraciones y convenciones universales (Domínguez \& Fernández, 2011), divididos a su vez, según se publica en la propia página web de Pacto Mundial (2016), en cuatro áreas principales en materia de derechos humanos, trabajo, medio ambiente y anticorrupción.

Strandberg (2010) expone que una empresa que participa en el Pacto Mundial se compromete a elaborar anualmente un informe de progreso dirigido a los grupos de interés, que describa los avances logrados por la empresa en la implementación de los diez principios, y se espera que la empresa los comparta con ellos. El propósito de la comunicación es que sea, por un lado, un sistema de autoevaluación -que las empresas identifiquen sus avances en las materias del Pacto- y, por otro lado, que dote de una mayor credibilidad a la iniciativa por medio de la transparencia. El objetivo de estos informes es que los participantes vayan progresando según los principios, y no necesariamente que cumplan todos ellos directamente.

Un dato relevante que apunta Strandberg (2010) es que el Pacto Mundial ha sido aplicado por más de 5.300 empresas en más de 130 países; un éxito del que se cree que depende de, en parte, de la reputación y la autoridad moral que tiene la ONU. Asimismo, los líderes empresariales consideran que su participación en el Pacto les ofrece muchas oportunidades y beneficios (García, 2004):

- Demostrar una posición de liderazgo en el ámbito de la responsabilidad cívica.

- Compartir experiencias y aprendizajes con empresas y organizaciones de la misma orientación. 
- Entablar relaciones con otras empresas, órganos gubernamentales, asociaciones de trabajadores, ONG y organizaciones internacionales.

- Asociarse con organismos de las Naciones Unidas.

- Aumentar al máximo las oportunidades comerciales ampliando la visión empresarial para abarcar la dimensión social y aplicando normas y prácticas de gestión responsable.

- Participar en diálogos orientados a la resolución de los problemas críticos que afronta el mundo, como la función de las empresas en zonas de conflicto.

Cabe señalar que estas empresas pertenecen a distintos sectores, pero sin embargo todas ellas comparten dos características: que son líderes y aspiran a un crecimiento mundial responsable, teniendo en cuenta los intereses y las preocupaciones de las partes interesadas (García, 2004).

\section{Global Reporting Initiative}

El modelo Global Reporting Initiative (GRI) se constituyó en 1997 como iniciativa no gubernamental en Estados Unidos (Cueto, 2014). Como describe Strandberg (2010), se trata de una organización basada en redes que fue creada por CERES, una red estadounidense de inversores, organizaciones ambientales y otros grupos de interés, con el Programa de las Naciones Unidas para el Medio Ambiente (PNUMA) como asociado.

Existen diferentes versiones de GRI, la última es la G4, que se lanzó en el año 2013 y que dio un gran salto, pasando de un enfoque de cumplimiento a poner en el eje central la gestión de la sostenibilidad. G4 presenta un nuevo formato que consta de dos partes: principios y contenidos estándares y manual de implementación (Cueto, 2014); y da una mayor importancia a los temas relevantes, librando así a las organizaciones de recopilar y proporcionar datos de asuntos de menor importancia, que frecuentemente requerían de una gran dedicación de esfuerzo y recursos (Scade, 2013).

Scade (2013) expone que G4 facilita la elaboración de informes de sostenibilidad haciéndolos más concisos al centrarse en asuntos realmente relevantes, contribuyendo así a una mayor transparencia, compromiso y confianza con los grupos de interés, lo cual genera valor. Además, hace posible que las memorias en sí mismas contribuyan a mejorar la gestión de la sostenibilidad en las organizaciones.

Las directrices de la GRI se refieren a principios respecto al contenido de las memorias (Strandberg, 2010) que cubren aquellos aspectos e indicadores que reflejen los impactos significativos (económicos, sociales y ambientales) de la organización o aquellos que podrían ejercer una influencia sustancial en la toma de decisiones de los grupos de interés a través de unos criterios exhaustivos que garanticen transparencia. 


\section{Libro verde}

El Libro verde se publicó en julio de 2001 y constituye la materialización del compromiso de la Unión Europea a favor de la RSC (Pinillos \& Fernández, 2011). Mediante un comportamiento socialmente responsable, las empresas pueden desempeñar un papel esencial para favorecer que la UE avance hacia su objetivo de mayor crecimiento económico, competitividad, justicia social y desarrollo sostenido (Pinillos \& Fernández, 2011). De hecho, la Comisión Europea (2010) manifiesta que este Libro ha resultado ser el marco europeo para promover la calidad y la coherencia de las prácticas de responsabilidad social, y el verdadero inicio del debate sobre cómo la Unión Europea podría fomentar la responsabilidad social de las empresas a nivel europeo e internacional.

Asimismo, propone fomentar prácticas correctas de las empresas, velar por la coherencia entre las políticas nacionales y los estándares internacionales, fomentar el partenariado (la asociación) entre empresa e interlocutores sociales, promover instrumentos de evaluación, animar a las empresas a adoptar un enfoque proactivo en relación al desarrollo sostenible, crear foros multistakeholders e incorporar prácticas de responsabilidad social en la gestión de gobierno (Comisión Europea, 2010).

Por último, considera que las políticas nacionales deben guardar relación con las políticas comunitarias y con los estándares y códigos internacionales. Es decir, el enfoque europeo de la RSC debe estar integrado en el contexto más amplio en el que se asientan otras iniciativas internacionales como el Pacto Mundial y las Directrices de la Organización para la Cooperación y el Desarrollo Económicos (OCDE), entre otras (Comisión Europea, 2010).

\section{AA1000 AccountAbility}

La serie de normas AA1000 fue creada por la organización británica AccountAbility, para ayudar a organizaciones a ser más responsables y sostenibles (Strandberg, 2010), evaluando distintos parámetros de comportamiento encaminados a medir la responsabilidad de estas y cómo se integran estos principios a su actividad diaria con todos los stakeholders (Pinillos \& Fernández, 2011).

Según publica en su página web Account Ability (2016), la serie de normas AA1000 de AccountAbility son normas y marcos basados en principios utilizados por un amplio espectro de organizaciones -empresas globales, empresas privadas, gobiernos y sociedades civiles- para demostrar liderazgo y desempeño en responsabilidad, responsabilidad y sostenibilidad.

Strandberg (2010) explica que los principios de esta norma proporcionan un marco para que una organización identifique, priorice y responda a los desafíos de su sostenibilidad, además de proveer una metodología profesional para evaluar la naturaleza 
y el grado en que una organización se adhiere a los Principios de AccountAbility. Por otro lado, sirve como patrón para ayudar a las organizaciones a reforzar el diseño, la ejecución y la evaluación de la participación de los grupos de interés y la comunicación con ellos.

\section{Organización para la Cooperación y el Desarrollo Económico}

La Organización para la Cooperación y el Desarrollo Económicos (OCDE) agrupa a 34 países miembros y su misión es promover políticas que mejoren el bienestar económico y social de las personas alrededor del mundo. (OCDE, s/f)

Las líneas directrices de la OCDE para empresas multinacionales, adoptadas en 1976, son recomendaciones dirigidas por los gobiernos a las empresas multinacionales. El objetivo principal de las directrices es garantizar que las actividades de esas empresas se desarrollen en armonía con las políticas públicas, y fortalecer la base de confianza mutua entre las empresas y las sociedades en las que desarrollan su actividad (Cueto, 2014).

El objetivo común de los gobiernos que han suscrito las directrices consiste en promover las contribuciones positivas al progreso económico, medioambiental y social que pueden tener las empresas multinacionales, y reducir al mínimo las dificultades que acusan sus diversas actividades (García, 2004).

Los principios de gobierno corporativo de la OCDE son (López \& Ríos, 2005) garantizar la base de un marco eficaz para el gobierno corporativo, así como los derechos de los accionistas a través de un trato equitativo en un entorno de transparencia corporativa.

\section{Otras regulaciones (ISO 26000, SA 8000 y Norma SGE 21)}

ISO 26000. La norma internacional ISO 26000, del 1 de noviembre de 2010, tiene como objetivos desarrollar un consenso internacional sobre qué significa la responsabilidad social y qué asuntos de la RSE tienen que abordar las organizaciones; proporcionar orientación sobre la puesta en práctica de los principios mediante acciones efectivas, y perfeccionar y divulgar información sobre mejores prácticas (Strandberg, 2010).

ISO 26000 contiene guías voluntarias, no requisitos, y por lo tanto no es para utilizar como una norma de certificación como la ISO 9001:2008 y la ISO 14001:2004 (ISO, 2010).

Así pues, de ISO 26000 se desprende una comprensión global relevante de lo que es la responsabilidad social y lo que las organizaciones tienen que hacer para operar de una manera socialmente responsable (ISO, 2010). 
SA 8000. La norma SA 8000 fue desarrollada en 1997 por Social Accountability International (SAI), una organización creada por varios grupos de interés que comparten el objetivo de mejorar el ejercicio de los derechos humanos de los trabajadores en todo el mundo (Strandberg, 2010).

Strandberg (2010) explica que la norma se orienta hacia los impactos sociales de la empresa, y se ocupa principalmente del trabajo infantil, el trabajo forzoso y obligatorio, la seguridad y la salud en el trabajo, los derechos de sindicación y de negociación colectiva, la discriminación, las medidas disciplinarias, el horario de trabajo, la remuneración y los sistemas de gestión.

Por tanto, tal y como manifiesta la Asociación Española para la Calidad (AEC, 2015), las organizaciones que así le deseen o que sean exigidas por mercados internacionales para poder exportar, deben comprobar que en sus procesos productivos se ofrecen condiciones de bienestar, de respeto a los derechos humanos, libre asociación, salarios justos, y no presentan ninguna forma de atropello ni discriminación.

La norma es una de las pocas que es certificable, aunque solo certifica a nivel de instalaciones y no a toda la empresa (Strandberg, 2010).

Norma SGE 21. La Norma SGE 21, desarrollada por la organización Forética en 1999, promueve un sistema de gestión ética y socialmente responsable que permite alcanzar la certificación (Strandberg, 2010). Es decir, pone a disposición de las organizaciones una sistemática enfocada a la integración voluntaria de sus preocupaciones sociales y medioambientales en las operaciones comerciales y en las relaciones con sus grupos de interés (Silos, 2016).

La norma fija los criterios que permiten a las organizaciones establecer, implantar y evaluar el SGE, el cual requiere un compromiso que demuestre al menos tres elementos esenciales: su integración en la estrategia y procesos de la organización, el impulso del diálogo y el conocimiento de las expectativas de los grupos de interés y, por último, el fomento de la transparencia y la comunicación (Strandberg, 2010).

Además, la norma presenta nueve áreas de gestión: la alta dirección, los clientes, los proveedores, las personas que integran la organización, el entorno social, el entorno ambiental, los inversores, la competencia y las Administraciones públicas (Strandberg, 2010).

\section{Sistemas específicos de gestión ambiental}

Existen numerosos Sistemas de Gestión Ambiental (SGA) destinados a todas aquellas organizaciones que deseen alcanzar un alto nivel de protección del medio ambiente, a base de acciones medioambientales y herramientas de gestión. De este modo, se garantizará una mejora en el comportamiento medioambiental de las organizaciones (Proyecto LIFE Sinergia, 2006). 
Y es que, como apunta Gómez (2009), un centro de actividad y su entorno se consideran subsistemas del sistema conjunto que entre ambos conforman.

Por tanto, la gestión ambiental se percibe como una parte indispensable de la gestión general en la organización, que puede producir grandes beneficios desde el punto de vista de la eficiencia y eficacia productiva, de la imagen que proyecta y de su promoción comercial (Gómez, 2009).

Como mencionábamos en el apartado anterior, la perspectiva en este caso sigue siendo de sistematización, a modo descriptivo y analítico.

\section{Norma ISO 14001}

La norma ISO 14001 pertenece a la serie de normas ISO 14000, la cual fue aprobada en 1996, aunque en Europa se adoptó en 1997 (García, 2004).

La serie de normas 14000 proporciona al gobierno corporativo las reglas y pautas para elaborar un sistema de gestión medioambiental que permita una mejora ambiental continua en sus procesos productivos (Cordero \& Sepúlveda, 2002). Es un conjunto de procedimientos que abarca diferentes aspectos de la gestión medioambiental, y son las normas derivadas 14001 y 14004 las especializadas en los sistemas de gestión medioambientales (Cueto, 2014).

Por su parte, la Norma ISO 14004 ofrece directrices para el desarrollo e implantación de los principios del Sistema de Gestión Ambiental (SGA) y las técnicas de soporte (García, 2004), pero en este trabajo nos centraremos en la Norma ISO 14001.

La norma ISO 14001 establece los criterios para un sistema de gestión ambiental y certificable, por lo que proporciona un marco que puede seguir una organización, independientemente del sector al que pertenezca, para establecer un sistema de gestión ambiental eficaz. Así pues, su uso puede proporcionar garantías al gobierno corporativo y a los empleados, así como a las partes interesadas externas (ISO, 2016). Cabe tener en cuenta además que esta norma incluye el requisito de compromiso de continua mejora y la obligación de cumplir la legislación y regulación relevantes (Roberts \& Robinson, 2003).

La certificación de la mencionada norma se basa en el análisis de la existencia de diferentes aspectos, entre los cuales destacan (Cueto, 2014) una política medioambiental claramente establecida y documentada, una revisión periódica de los objetivos de esta política, una valoración del impacto ambiental de las operaciones y productos en términos de su probabilidad y gravedad, el establecimiento de objetivos específicos y medibles, la implicación de los empleados de la organización, la generación de un plan de actuación, con revisión periódica y la mejora continua.

El objetivo general, tanto de la ISO 14001, como del resto de normas de la serie 14000, es apoyar la protección medio ambiental y la prevención de la contaminación en armonía con las necesidades socioeconómicas (Roberts \& Robinson, 2003). 


\section{Eco-Management and Audit Scheme}

El Sistema de gestión y Auditoría Medioambiental Reglamento Comunitario de Ecogestión y Auditoría (Eco-Management and Audit Scheme, EMAS) es un instrumento voluntario de gestión y de alta calidad desarrollado por la Unión Europea en 1993, que reconoce a aquellas organizaciones que han implantado un Sistema de Gestión Ambiental y que han adquirido un compromiso de mejora continua, verificado mediante auditorías independientes (Cueto, 2014; Departamento de Territorio y Sostenibilidad, 2014).

Las organizaciones reconocidas con el EMAS tienen una política ambiental definida, hacen uso de un sistema de gestión medioambiental y dan cuenta periódicamente del funcionamiento de este sistema a través de una declaración medioambiental verificada por organismos independientes, según publica el Ministerio de Agricultura y Pesca, Alimentación y Medio Ambiente de España.

El objetivo general de EMAS es asumir una responsabilidad ambiental y económica, mejorar su comportamiento ambiental y comunicar sus resultados ambientales a la sociedad y a las partes interesadas en general (Departamento de Territorio y Sostenibilidad, 2014).

\section{Caso de estudio: CESPA (Ferrovial)}

Para el caso de estudio se ha escogido como ejemplar a CESPA gestión de residuos, dado que es una empresa que se dedica a la prestación de servicios medioambientales y a la gestión y tratamiento de residuos.

Distintos miembros del equipo de CESPA aseguran realizar un esfuerzo diario constante para ser líderes en la gestión y tratamiento de residuos, y velan por la protección del medio ambiente, la formación de los trabajadores y la seguridad del entorno laboral.

CESPA no dispone de una RSC propia y personalizada, sino que está englobada dentro del marco de la RSC del grupo Ferrovial, por lo que en este estudio analizaremos la del grupo.

CESPA está participada íntegramente por el grupo Ferrovial, a través de la Dirección General de Servicios, y es un referente mundial en la prestación de servicios medioambientales y en la gestión y tratamiento de residuos. Actualmente está presente en España, Portugal, Reino Unido y Polonia.

La empresa CESPA se fundó en 1970 con el fin de dar servicio a las exigencias ambientales de los municipios y otras entidades públicas. Su actividad inicial se centró en los servicios de recogida de residuos y limpieza viaria. Con el transcurso de los años, los servicios medioambientales que presta CESPA se han ido ampliando, mejorando y consolidando enormemente, de forma que en la actualidad abarcan casi todas las actividades relativas a la gestión de todo tipo de residuos. 
Sus principales cifras son:

- Más de 15.000 empleados.

- Más de 320 centros de trabajo.

- Servicios en más de 800 municipios en España, Portugal, Reino Unido y Polonia.

- Gestión de más de 7 millones de toneladas anuales de residuos.

- Mantenimiento de más de 25 millones de metros cuadrados de jardinería.

- Más de 170 instalaciones de tratamiento.

- Flota propia de más de 7.500 vehículos.

Por su parte, el grupo Ferrovial se define como uno de los principales operadores globales de infraestructuras y gestores de servicios a ciudades, comprometido con el desarrollo de soluciones sostenibles. Su estructura se divide en cuatro líneas de negocio: autopistas, construcción, aeropuertos y servicios, y es esta última división la que acoge CESPA dentro de las diferentes empresas del grupo que giran en torno a servicios urbanos medioambientales; mantenimiento de infraestructuras, y foco en ciudades inteligentes, revalorización del residuo y eficiencia energética.

En cuanto al área específica de la RSC, cabe detallar que Ferrovial cuenta con un Comité de Responsabilidad Social responsable de desarrollar, implantar y supervisar las políticas de responsabilidad social. El comité se constituye en el nexo de unión de los negocios y la corporación con la alta dirección, reportando resultados y proponiendo iniciativas en materia de responsabilidad social. Está integrado por las distintas áreas de la compañía vinculadas a la responsabilidad corporativa (recursos humanos, calidad y medio ambiente, innovación, riesgos, secretaría general y comunicación y responsabilidad corporativa) y por un representante de cada línea de negocio (servicios, autopistas, construcción y aeropuertos).

\section{Resultados}

Una vez contrastados los datos de la investigación teórica, de fuentes públicas y privadas sobre los principales modelos de medición, y las entrevistas de los responsables de la aplicación de la RSC en el caso estudiado, a continuación presentamos de forma resumida los resultados obtenidos de la investigación. Los datos se presentan en bloques temáticos, centrados primero en las principales líneas estratégicas utilizadas en la gestión de la RSC para luego ver cómo esas líneas estratégicas afectan el desarrollo de la comunicación de la empresa que nos ocupa.

\section{Las líneas estratégicas de la RSC}

Ferrovial, a través del Plan Estratégico de Responsabilidad Corporativa, llamado Plan 20.16, pretende mejorar su competitividad, desarrollar la sostenibili- 
dad de la compañía y proteger su reputación, aportando valor a largo plazo todos los stakeholders.

Este plan, vigente desde enero de 2014, es fruto de la actualización y revisión del plan anterior con el que se logró vincular la Responsabilidad Corporativa con los objetivos de negocio de la compañía, y en concreto acercarla al posicionamiento en Infraestructuras Inteligentes que define a Ferrovial. Otro de los logros fue la creación, en 2010, del Comité de Responsabilidad Corporativa constituido como nexo de unión entre los negocios y la corporación con la alta dirección.

Como línea estratégica en RSC, el actual plan 20.16 incorpora las palabras del presidente: "Ferrovial, como referente en el sector de infraestructuras y servicios, contribuirá a mejorar el futuro de la sociedad con una continua apuesta por el talento, la integridad, la seguridad, la excelencia y la innovación" (Plan Estratégico de Responsabilidad Corporativa Ferrovial, 2014).

Las distintas áreas y líneas de actuación en materia de RSC quedan plasmadas en el Plan 20.16 en los siguientes aspectos: gobierno corporativo, a través de la transparencia en la información al mercado; ética e integridad, generando y siguiendo códigos de conductos, respetando los derechos humanos y facilitando la cadena de suministro; personas, a través de la atracción y retención de talento e igualdad de oportunidades; medio ambiente, centrado especialmente en el cambio climático y la eco-eficiencia; sociedad, con un trabajo centrado en la comunidad y con la intención de dejar huella social; y por último innovación, a través de fomento al emprendimiento y el desarrollo sostenible.

Ferrovial, tras concretar las áreas y líneas de actuación, define en el mencionado Plan 20.16 una serie de programas prioritarios para centrar sus recursos en materia de RSC, alineados siempre con su actividad de negocio.

\section{Instrumentos de gestión}

Ferrovial mantiene su compromiso con la calidad y el medio ambiente, pues todas las áreas de negocio tienen implantados en sus contratos sistemas de calidad y medio ambiente certificados conforme a la norma ISO 9001 y 14001.

Cabe especificar que, en el caso de la norma ISO 14001, el alcance de certificación de los sistemas en cada empresa y en el total del grupo se evalúa mediante el indicador "Porcentaje de Ventas Certificadas". En este ratio se contabilizan exclusivamente las actividades que están amparadas por el alcance de los correspondientes certificados de sistemas de gestión medioambiental, a partir del Importe Neto de la Cifra de Negocio (INCN). El porcentaje de actividad certificada en medio ambiente en 2015 ha sido $90 \%$.

Ferrovial presenta también su información económica, social y ambiental siguiendo los principios del Marco Conceptual para la preparación del informe Integrado del International Integrated Reporting Council (IIRC). 
Asimismo, la información de RSC aplica por séptimo año los principios de la norma AA1000, una herramienta clave para la alineación de la información presentada en el Informe con las expectativas de sus grupos de interés y la materialidad de la compañía. El informe sigue la cuarta versión de la Guía del Global Reporting Initiative (GRI) con auto-declaración "Comprehensive", según los requisitos de la Guía GRI.

Ferrovial dispone de certificaciones como la norma ISAE 3410, que consiste en la verificación externa de sus emisiones de gases de efecto invernadero. Esta verificación incluye todas sus divisiones y tanto las emisiones directas como indirectas correspondientes a los alcances 1,2 y 3 . Igualmente verifica que el procedimiento interno "Cálculo y Reporte de la Huella de Carbono" cumple con lo señalado en el estándar internacional ISO 14064-1.

Entre otras, también destacan Integrated Management System PAS 99 y Specification PAS for composted materials and Quality Compost; así como UNE-EN 12899-1:2009; UNE 135332:2005; UNE 166002; UNE 179002; ISO 50001:2011; ISO 22000, ISO 39001, BS 1100, EMAS y Madrid Excelente.

En materia de sostenibilidad, Ferrovial demuestra su compromiso a través de la adhesión a distintas iniciativas internacionales, como a la declaración tripartita de la OIT (Organización Internacional del Trabajo). La OIT es la institución mundial responsable de la elaboración y supervisión de las normas internacionales del trabajo. Sus objetivos principales son promover los derechos laborales, fomentar oportunidades de trabajo decente, mejorar la protección social y fortalecer el diálogo al abordar los temas relacionados con el trabajo.

Su misión es promover políticas que mejoren el bienestar económico y social de las personas alrededor del mundo. Además, trabaja para entender qué conduce al cambio económico, social y ambiental; mide la productividad y los flujos globales del comercio e inversión; analiza y compara datos para realizar pronósticos de tendencias, y fija estándares internacionales dentro de un amplio rango de temas de políticas públicas.

\section{Estrategias de comunicación}

Ferrovial mantiene una relación fluida con los grupos de interés más relevantes. En este contexto, se consideran especialmente importantes las relaciones mantenidas con los analistas e inversores especializados en Inversión Socialmente Responsable (ISR), con los portavoces de la sociedad civil (ONG y sindicatos, principalmente), los gobiernos y reguladores, así como con las comunidades locales.

En el caso particular de las ONG, y otros representantes de la sociedad civil, Ferrovial busca proyectos de interés común con algunas de las más relevantes organizaciones dedicadas a la conservación, como World Wildlife Found (WWF), que tiene como misión detener la degradación ambiental del planeta y construir un futuro en 
el que el ser humano viva en armonía con la naturaleza conservando la diversidad biológica mundial, asegurando que el uso de los recursos naturales renovables sea sostenible y promoviendo la reducción de la contaminación y el consumo desmedido.

La compañía colabora también en distintos proyectos con organizaciones, e incluso en algunos casos con instituciones vinculadas a la administración pública, además de llevar a cabo proyectos relevantes de interés común con SEO-Birdlife (Sociedad Española de Ornitología), organización pionera de la conservación de la naturaleza y la biodiversidad en España.

\section{Implicaciones de la aplicación de la RSC}

A nivel económico, según el Informe Anual Integrado 2015 publicado, Ferrovial cerró el pasado ejercicio con una sana situación financiera y de negocio. Los resultados alcanzados por la compañía son consecuencia del buen comportamiento operativo de los negocios, junto a una política de rotación de activos que aportó ingresos no recurrentes. Concretamente, la cartera de Servicios y Construcción registró máximos históricos al sobrepasar los 31.500 millones de euros, lo que representa una garantía de actividad futura.

En lo que respecta al posicionamiento de Ferrovial frente a la competencia, cabe señalar que la compañía se consolida entre las compañías reconocidas por los exigentes índices Dow Jones Sustainability Index, FTSE4Good y Carbon Disclosure Project, lo que denota su compromiso con la RSC y el medio ambiente. El trabajo y el esfuerzo llevado a cabo por la compañía y sus empleados son reconocidos por los grupos de interés y las distintas entidades en todos los ámbitos de su actividad y de la RSC. Prueba de ello son los premios y reconocimientos que la empresa ha obtenido en los últimos años, entre los cuales se destacan aquellos que guardan mayor relación con el ámbito de la RSC.

En el año 2016, Ferrovial ha sido reconocida por sexta vez consecutiva en los galardones Top Employer España 2016, demostrando así su compromiso con el talento humano, fomentando la atracción, la retención y el desarrollo de los empleados. Ese galardón es fruto de haber implantado en el transcurso del último año una serie de medidas y buenas prácticas para garantizar la atracción y la retención del mejor talento interno. Al mismo tiempo, ha promovido un buen clima laboral a través de distintas acciones como resultado de la Encuesta de Clima de 2015.

En 2015, la red profesional LinkedIn Talent Solutions celebró por primera vez los Premios IN 2015, en la que premió la estrategia de comunicación en social media y digitalización de Ferrovial, así como el haber sabido transmitir mejor sus mensajes al público desde el perfil social.

En 2015 también se celebró la XXIII Edición de los premios que la revista Actualidad Económica desarrolla para buscar e incentivar la innovación de los productos y servi- 
cios más brillantes, útiles e innovadores puestos en marcha en 2014. En esta edición, el Clúster Medioambiental del Ayuntamiento de Murcia, gestionado por Ferrovial, fue galardonado como una de las mejores ideas sostenibles del país. Su finalidad es aglutinar en el mismo espacio empresas y colaboraciones relacionadas con la calidad ambiental, la investigación en eficiencia energética, así como en el desarrollo e innovación dentro del campo del tratamiento y valorización de residuos.

En 2014, Ferrovial renovó una vez más su presencia en la serie de Índices FTSE4Good, lo que significa diez años de permanencia en el índice. La compañía fue seleccionada como resultado de su desempeño y mejora en materia de RSC.

\section{Conclusiones}

El trabajo de investigación realizado de la RSC en el ámbito del comportamiento de las empresas medioambientales lleva a las siguientes conclusiones.

Tiempo atrás, la RSC guardaba directa relación con las actividades filantrópicas que pudiesen llevar a cabo las empresas. Sin embargo, ello ha cambiado, y es el foco de la RSC el que las empresas desarrollen, durante sus operaciones de negocio, relaciones responsables con sus grupos de interés (stakeholders). Es decir, la RSC podría ser definida como una colección de políticas y prácticas relacionadas con una relación con depositarios clave, valores, conformidad con requerimientos legales, y respeto por la gente, las comunidades y el ambiente; además del compromiso de las empresas a contribuir para el desarrollo sustentable.

Así pues, es evidente que la RSC se ha convertido en un reto para las organizaciones. Cada vez son más las empresas que, de forma voluntaria, asumen plenamente la responsabilidad social, y son conscientes de la importancia y del beneficio que aporta al mejorar su situación competitiva, valorativa, su reputación corporativa y su valor añadido. La integración de la responsabilidad social va más allá de la maximización del beneficio para el accionista, pues conlleva para la empresa una mejora de los resultados económicos a medio y largo plazo.

El estudio de la RSC presenta una multitud de teorías que sugieren una complementariedad y racionalidad profunda que, tal y como hemos analizado, puede ser de tipo jurídico y económico o de tipo ético, psicológico y sociólogo.

La RSC incorpora una triple dimensión: económica, social y medioambiental, tres pilares que contribuyen al desarrollo sostenible, el cual se sitúa como fin a alcanzar por medio de la adecuada implantación de un modelo de empresa socialmente responsable. $\mathrm{Y}$ es que la preocupación por los aspectos sociales y medioambientales la padece tanto el sector privado como el público, con la diferencia que el sector privado ha tomado iniciativas en este sentido y el sector público está justo comenzando a ser consciente de ello. 
La medición y la valoración del grado de aplicación de la RSC se lleva a cabo mediante distintos instrumentos, en esta investigación hemos convenido profundizar en algunos de ellos, como en las más relevantes y comunes regulaciones internacionales Global Compact, Global Reporting Initiative (GRI) y Libro Verde, entre otras; así como en los principales sistemas específicos de gestión ambiental ISO 14001 y EcoManagement and Scheme (EMAS). Cada uno de estos instrumentos consta de una serie de normas y procesos a seguir para alcanzar las diferentes certificaciones, según el nivel de aplicación de la RSC y el alcance de la empresa.

En cualquier caso, consideramos la necesidad de seguir estimulando las prácticas positivas de las empresas y administraciones públicas, promover la implantación de sistemas eficientes de gestión y fomentar los procesos de mejora continua.

A modo de conclusión del caso práctico realizado sobre la empresa CESPA (Ferrovial), hemos podido constatar que la RSC de CESPA se remite a la del grupo Ferrovial, el cual dispone de una avanzada y reconocida implantación de RSC. El grupo Ferrovial pretende con la RSC mejorar la competitividad, desarrollar la sostenibilidad de la compañía y proteger su reputación, aportando valor a largo plazo para todos los stakeholders.

El propio Comité de Responsabilidad Social de Ferrovial realiza un excelente trabajo en esta materia de RSC, con una visión estratégica para seguir siendo referente en el sector y orientada a la mejora continua.

\section{Referencias}

Adams, C., Hill, W. \& Roberts, C. (1998). Corporate social reporting practices in Western Europe: legitimating corporate behavior? British Accounting Review, 30 (1), 1-21.

Alea, A. (2007). Responsabilidad social empresarial. Su contribución al desarrollo sostenible. Revista Futuros, 5 (17). Recuperado de http://abiunsa.edu.pe/wpcontent/uploads/2014/01/Responsabilidad-Social-Empresarial.pdf.

Aranda, D. (1994). Elementos de delimitación del sector medioambiental: ecoactividades. Economía Industrial, mayo-junio, 297,19-25.

Argandoña, A. (2005). Empresa, Economía de mercado y Responsabilidad social. Pamplona: IESE - Universidad de Navarra (Documento de investigación de la Cátedra Economía y Ética, DI 600). Recuperado de http://www.iese.edu/research/ pdfs/DI-0600.pdf.

Argandoña, A. (2006). Milton Friedman (1912-2006). Pamplona: IESE - Universidad de Navarra (Cuadernos de la Cátedra "La Caixa" de Responsabilidad Social de la Empresa y Gobierno Corporativo, OP 07/9). Recuperado de http://www.iese.edu/ research/pdfs/OP-07-09.pdf. 
Argandoña, A. (2008). La responsabilidad social de las empresas pequeñas y medianas. Pamplona: IESE - Universidad de Navarra (Cuadernos de la Cátedra "La Caixa" de Responsabilidad Social de la Empresa y Gobierno Corporativo, 1). Recuperado de http://www.iese.edu/es/files_html/5_40821.pdf.

Argandoña, A. (2009). La evolución del concepto stakeholders en los escritos de Ed Freeman. Pamplona: IESE - Universidad de Navarra, 5. Recuperado de http:// www.iese.edu/es/files/La\%20evaluaci\%C3\%B3n\%20del\%20concepto\%20de\%20 stakeholders\%20seg\%C3\%BAn\%20Freeman_tcm5-39688.pdf.

Asociación Española de Contabilidad y Administración de Empresas (AECA). (2004). Marco Conceptual de la Responsabilidad Social Corporativa. Madrid.

Avendaño, W. R. (2011). Responsabilidad Social Corporativa (RSC) y Desarrollo Sostenible: una mirada desde la Declaración de Rio de 1992. Cúcuta: Universidad Francisco de Paula Santander. 16 (2), 45-59. Recuperado de http://revistas.ufps. edu.co/ojs/index.php/respuestas/article/view/360.

Cancino, C. \& Morales, M. (2008). Responsabilidad Social Empresarial. Chile: Facultad Economía y Negocios Universidad de Chile. Recuperado de https://www. researchgate.net/publication/43650508_responsabilidad_social_empresarial.

Capriotti, P. \& Schulze, F. (2010). Responsabilidad Social Empresarial. Barcelona - Santiago (Chile): Executive Business School, Recuperado de http://www. bidireccional.net/Blog/Libro_RSE.pdf.

Carroll, A. (1979). A Three-Dimensional Conceptual Model of Corporate Performance. The Academy of Management Review, 4 (4), 497-505.

Carroll, A. (1983). Corporate social responsibility involves the conduct. Georgia: University of Georgia Business.

Casado, F. (2006). La RSE ante el espejo. Carencias complejos y expectativas de la empresa responsable en el siglo XXI. Zaragoza: Prensas Universitarias de Zaragoza.

Chirinos, M. E., Fernández, L. \& Sánchez, G. (2012). Responsabilidad Empresarial o Empresas Socialmente Responsables. Razón y Palabra, 81. Recuperado de http://www. razonypalabra.org.mx/N/N81/M81/02_ChirinosFernandezSanchez_M81.pdf.

Cordero, P. \& Sepúlveda, S. (2002). Sistemas de Gestión Medio Ambiental: Las normas ISO 14000. Cuadernos técnicos IICA, 21.

Correa, J. G. (2007). Evolución histórica de los conceptos de responsabilidad social empresarial y balance social. Semestre Económico, 10 (20), 87-102. Recuperado de http://revistas.udem.edu.co/index. php/economico/article/view/682/623.

Cueto Cedillo, C. (2014). La responsabilidad social corporativa del sector público: un análisis aplicado a las grandes ciudades en España. (Tesis). Universidad Nacional de Educación a Distancia, Madrid. Recuperado de http://e-spacio.uned.es/fez/view/ tesisuned:CiencEcoEmp-Ccueto. 
Díaz I Pont, J.(2007). Responsabilitat corporativa i sostenibilitat: actors socials, comunicació i governança. (Tesis). Universitat Autònoma de Barcelona, Barcelona. Recuperado de https://dd.uab.cat/pub/tesis/2007/tdx-1005107-163211/jdp1de1.pdf.

Domínguez, R. \& Fernández, J. (2011). Responsabilidad Social Corporativa. Cantabria: CEOE CEPYME. Recuperado de http://www.ciberoamericana.com/pdf/Guial_ RSC.pdf.

Fernández, R.(s/f).Obligaciones de la empresa con la sociedad. Alicante: ECU - Editorial Club Universitario.

Freeman, R. E. \& Mcvea, J. (2001). A Stakeholder Approach to Strategic Management. The Darden School University of Virginia. Recuperado de https://www.researchgate.net/ publication/228320877_A_Stakeholder_Approach_to_Strategic_Management.

Garcés, C. \& Ramírez, M. (2002). Análisis del alcance estratégico de las empresas del sector medioambiental en España, Economía Industrial. 343, 161-169. Recuperado de http://www. minetad.gob.es/Publicaciones/Publicacionesperiodicas/ EconomiaIndustrial/RevistaEconomiaIndustrial/343/161-GARCES.pdf.

García, M. J. (2004). RSC círculo virtuoso: rentabilidad-medioambiente (Tesis). Madrid: Universidad Politécnica de Madrid. Recuperado de http://oa.upm. es/327/1/07200429.pdf.

Garriga, E. \& Melé, D. (2004). Corporate Social Responsibility Theories: Mapping the Territory. Journal of Business Ethics, 53 (1), 51-71. Recuperado de https://link. springer. com/article/10. 1023/B:BUSI. 0000039399. 90587.34.

Gismera, L. \& Vaquero, M.E. (2000). La responsabilidad social de la empresa en España: La acción social. Papeles de Ética, Economía y Dirección, 5, 1-8. Recuperado de http://www. eticaed.org/9.Gismera-Vaquero00.pdf._

Gómez,D. (2009).La gestión ambiental de la empresa. Responsabilidades de productores y consumidores. Economía industrial, 371, 87-100. Recuperado de http://www. minetad.gob.es/Publicaciones/Publicacionesperiodicas/EconomiaIndustrial/ RevistaEconomiaIndustrial/371/87.pdf.

González,J.,Gento,A.M., \& Olivella,J.(2013). Modelo de indicadores de responsabilidad social empresarial para el sector de la logística y el transporte. Técnica Industrial, 303, 22-32. Recuperado de http://docplayer. es/6448149-... -el-transporte. html.

Ligteringen, E. y S. Zadek (2005), Future of Corporate Responsability codes, standards and frameworks, Global Reporting Initiative. AccountAbility. Institute of Social and Ethical AccountAbility. Recuperado de: https://www.greenbiz.com/sites/ default/files/document/CustomO16C45F63376.pdf

Lafuente, A., Viñuales, V., Pueyo, R. \& Llaría, J. (2003). Responsabilidad Social Corporativa y Políticas Públicas. Fundación Alternativas. Recuperado de http:// ecodes. org/documentos/archivo/ecodes_fa_rsc_politicas_publicas.pdf. 
Logsdon, J. M. \& Wood, D. J. (2002). Business Citizenship: From Individuals to Organizations. Business Ethics Quarterly, Ruffin Series, 3, 59-94. Recuperado de https://papers.ssrn.com/sol3/papers.cfm?abstract_id $=1512277$

Ludevid, M. (2000). La gestión ambiental de la empresa. Barcelona: Editorial Ariel.

Madrakhimova, F. (2013). Evolution Of The Concept And Definition Of Corporate Social Responsibility. Global Conference on Business and Finance Proceedings, 8 (2), 113-118. Recuperado de http://www.uona.edu/UoNA/files/literature/3229.2342_ ISSN-1941-9589-V8-N2-2013_a.pdf.

Marín,J.L. \& Rubio,A.(2008). La responsabilidad social corporativa como determinante del éxito competitivo: un análisis empírico. Revista Europea de Dirección y Economía de la Empresa, Universidad de Murcia, Murcia. 17 (3), 27-42. Recuperado de http:// www.aedem-virtual. com/articulos/123686287600.pdf.

Moneva, J. M. (2005). Información sobre responsabilidad social corporativa: situación y tendencias. Revista asturiana de economía, 34, 43-55. Recuperado de http://www. revistaasturianadeeconomia.org/raepdf/34/MONEVA.pdf.

Moneva, J. M. (2008). ¿Es la responsabilidad social corporativa rentable para la empresa? Revista de contabilidad y dirección, 7, 55-74. Recuperado: http://www. accid.org/revista/castellano/fitxa_revista.php?num=7\&idi=ES

Moreno, J. A. (2004). Responsabilidad social corporativa y competitividad: una visión desde la empresa. Revista Valenciana de Economía y Hacienda. 12, 9-50.

Moreno, M. J., Vaca, R. M. \& Riquel, F. (2007). Análisis de la responsabilidad social corporativa desde tres enfoques: stakeholders, capital intelectual y teoría institucional. Huelva: Universidad de Huelva.

Navarro Espigares, J. \& Hernández Torres, E. (2005). Responsabilidad social corporativa en el ámbito del sector público. Universidad de Granada, Granada. Recuperado de http://www.asepelt.org/ficheros/File/Anales/2005\%20-\%20Badajoz/ comunicaciones/responsabilidad\%20social\%20corporativa....pdf.

Organización para la Cooperación y el Desarrollo Económicos (2005). Resumen de los principios de la OCDE para el gobierno corporativo. Contaduría y Administración, mayo-agosto, 169-182. Recuperado de http://www.ejournal.unam.mx/rca/216/ RCA21608.pdf

Pinillos, A. \& Fernández, J. L. (2011). De la RSC a la sostenibilidad corporativa: una evolución necesaria para la creación de valor. Harvard Deusto Business Review, diciembre, 5-21. Recuperado de http://gacconsultores.com/novedades/ FICHA_16032015154525.pdf.

Porter, M. \& Kramer M. (2006). Estrategia y sociedad. Harvard Business Review, 84 (12), 42-56.

Porter, M. \& Kramer M. (2011). La creación de valor compartido. Harvard Business 
Review, Enero-febrero, 3-18. Recuperado de: https://www.google.es/search?q=La+ creaci\%C3\%B3n+de+valor+compartido. + Harvard+Business $+\& i e=u t f-8 \& o e=u t f-$ $8 \&$ client $=$ firefox-b-ab\&gfe_rd $=c r \& d c r=0 \& e i=96 \mathrm{mvWe} 6 \mathrm{eK} 4 \mathrm{eq} 4 \mathrm{gTSnKPICg}$

Ricart, J. E. \& Rodríguez, M. A. (2002). Código de gobierno para la empresa sostenible. Pamplona: IESE - Universidad de Navarra. Recuperado de http://www.iese. edu/ research/pdfs/ESTUDIO-94.pdf.

Roberts, H. \& Robinson, G. (2003). EMS Manual de sistema de gestión medioambiental, ISO 14001. Thomson Editores, Madrid.

Scade, J. (31 de mayo de 2013). La nueva Guía G4 del GRI presenta grandes novedades para las memorias de sostenibilidad. [Editorial] Revista Compromiso Empresarial. Recuperado de http://www.compromisoempresarial.com/rsc/2013/05/la-nuevaguia-g4-del-gri-se-presenta-con-grandes-novedades-para-las-memorias-desostenibilidad/

Silos, J. (Dir.). (2015). Informe Forética 2015 sobre el estado de la RSE en España. Ciudadano consciente, empresas sostenibles. Madrid: Forética. Recuperado de http://foretica.org/informe_foretica_2015.pdf.

Strandberg, L. (2010). La medición y la comunicación de la RSE: indicadores y normas. Pamplona: IESE - Universidad de Navarra (Cuadernos de la Cátedra "La Caixa" de Responsabilidad Social de la Empresa y Gobierno Corporativo, 9). Recuperado de http://www.iese.edu/en/files/Cuaderno\%20No\%209_tcm4-57352.pdf.

Suárez, S. Y. \& Pérez, C. A. (2010). Responsabilidad social empresarial. Bogotá: Universidad Militar Nueva Granada. Recuperado de http://unimilitar-dspace. metabiblioteca.org/bitstream/10654/3721/2/SuarezSantosSandraYaneth2010.pdf. Travassos, M. F. (2014). Diseño de indices de divulgación de la información de responsabilidad social empresarial y gobierno corporativo. Extremadura: Universidad de Extremadura.

\section{Sitios web de consulta}

Accountability. Recuperado el 23 de enero de 2017: http://www.accountability.org/. Asociación Española para la Calidad (AEC). Recuperado el 23 de enero de 2017: http:// www.aec.es/web/guest/centro-conocimiento/sa-8000.

BOE, Ley 2/2011 de 4 de marzo, de Economía Sostenible. Recuperado el 23 de enero de 2017: https://www.boe.es/buscar/act.php?id=BOE-A-2011-4117.

Comisión Europea. Recuperado el 23 de enero de 2017: http://ec.europa.eu/ index_es.htm.

Comisión de las Comunidades Europeas. Recuperado el 23 de enero de 2017: http:// www.um.es/rscpymes/ficheros/RSC_...Desarrollo_Sostenible_2002.pdf.

Consejo Empresarial Mundial para el Desarrollo Sostenible, (World Business Council 
for Sustainable Development -WBCSD-). Recuperado el 23 de enero de 2017: http://www.wbcsd.org/.

Departamento de Territorio y Sostenibilidad. Recuperado el 23 de enero de 2017: http://mediambient.gencat.cat/es/05_.../que_es_lemas/index.html.

EMAS. Recuperado el 23 de enero de 2017: http://ec.europa.eu/environment/emas/ index_en.htm.

Fundación Conama. Recuperado el 23 de enero de 2017: http://www.conama.org/web/ index.php?lang=es.

Global Reporting Initiative. Recuperado el 23 de enero de 2017: https://www. globalreporting.org/Pages/default.aspx.

GREEN. Recuperado el 23 de enero de 2017: http://www.greenjobsproject.eu/fotos/... Medioambiental\%20Vasco.pdf.

Green Building Council España (GBCe). Recuperado el 23 de enero de 2017: http:// www.gbce.es/.

KPMG. Recuperado el 23 de enero de 2017: https://home.kpmg.com/es/es/home.html

Libro Verde. Recuperado el 23 de enero de 2017: http://eur-lex.europa.eu/ legal-content/...\&from=ES.

Ministerio de Agricultura y Pesca, Alimentación y Medio Ambiente. Recuperado el 23 de enero de 2017: http://www.mapama.gob.es/es/...-ecoauditoria-emas/.

Observatorio de Responsabilidad Social Corporativa. Recuperado el 23 de enero de 2017: http://observatoriorsc.org/libro-verde-...-social-de-las-empresas/.

OCDE (Organización para la Cooperación y el Desarrollo Económicos). Recuperado el 23 de enero de 2017: http://www.oecd.org/centrodemexico/laocde/.

Organización de las Naciones Unidas, para la Educación, la Ciencia y la Cultura, la Educación para el Desarrollo Sostenible (Libro de consulta). Recuperado el 23 de enero de 2017: http://unesdoc.unesco.org/images/0021/002167/216756s.pdf.

Organización Internacional de Normalización (ISO). Recuperado el 23 de enero de 2017: http://www.iso.org/iso/home/standards/management-standards/iso14000.htm.

Pacto Mundial. Recuperado el 23 de enero de 2017: http://www.pactomundial.org/.

Programa de seguimiento de cambio global. Recuperado el 23 de enero de 2017: http:// www.mapama.gob.es/es/red-parques-nacionales.../default.aspx.

SEO-Birdlife (Sociedad Española de Ornitología). Recuperado el 23 de enero de 2017: http://www.seo.org/.

Sistemas de gestión ambiental (SGA), Proyecto LIFE Sinergia. Recuperado el 23 de enero de 2017: http://www.lifesinergia.org/formacion/curso/12_sistemas_... ambient.pdf.

Social Accountability International. Recuperado el 23 de enero de 2017: http://www. sa-intl.org/. 